\title{
Cellular FLICE/Caspase-8-Inhibitory Protein as a Principal Regulator of Cell Death and Survival in Human Hepatocellular Carcinoma
}

\author{
Hiroshi Okano, Katsuya Shiraki, Hidekazu Inoue, Tomoyuki Kawakita, \\ Takenari Yamanaka, Masatoshi Deguchi, Kazushi Sugimoto, Takahisa Sakai, \\ Shigeru Ohmori, Katsuhiko Fujikawa, Kazumoto Murata, and Takeshi Nakano
}

First Department of Internal Medicine (HO, K. Shiraki, HI, TK, TY, MD, K. Sugimoto, TS, SO, KF, KM, TN), Mie

University School of Medicine, Tsu, Mie, Japan

\begin{abstract}
SUMMARY: Human hepatocellular carcinomas (HCCs) show resistance to apoptosis mediated by several death receptors. Because cellular FLICE/caspase-8-inhibitory protein (cFLIP) is a recently identified intracellular inhibitor of caspase-8 activation that potently inhibits death signaling mediated by all known death receptors, including Fas, TNF-receptor (TNF-R), and TNF-related apoptosis-inducing ligand receptors (TRAIL-Rs), we investigated the expression and function of cFLIP in human HCCs. We found that cFLIP is constitutively expressed in all human HCC cell lines and is expressed more in human HCC tissues than in nontumor liver tissues. Metabolic inhibitors, actinomycin D (ActD) or cycloheximide (CHX), dramatically rendered HCC cells sensitive to Fas-mediated apoptosis. Neither caspase-8 nor caspase-3 was activated by agonistic anti-Fas antibody alone, but both caspases were activated by Fas stimulation in the presence of ActD or CHX, indicating the importance of caspase-8 inhibitors that are sensitive to metabolic inhibitors. Actually, cFLIP expression was decreased in ActD or CHX treatment. cFLIP down-regulation induced by cFLIP antisense oligodeoxynucleotides sensitized HLE cells to Fas, TNF-R, and TRAIL-R-mediated apoptosis. Furthermore, cFLIP over-expression activated nuclear factor (NF)- $\kappa \mathrm{B}$ and cFLIP down-regulation attenuated NF- $\kappa \mathrm{B}$ activation induced by TNF- $\alpha$ or TRAIL. Pretreatment with pan-caspase-inhibitor, benzyloxycarbonyl-Val-Ala-Asp (OMe) fluoromethyl ketone (Z-VAD-fmk), restored NF- $\kappa$ B activity attenuated by cFLIP down-regulation. cFLIP expression was increased by TNF- $\alpha$, TRAIL, or vascular endothelial growth factor but decreased by wortmannin, indicating that cFLIP expression is regulated by both the NF- $\kappa$ B and phosphatidylinostiol-3 kinase (PI-3)/Akt pathways. These results suggest that cFLIP plays an important role in cell survival not simply by inhibiting death-receptor-mediated apoptosis but also by regulating NF- $\kappa$ B activation in human HCCs. (Lab Invest 2003, 83:1033-1043).
\end{abstract}

$A$ poptosis, or programmed cell death, is a key mechanism regulating various physiologic events, including the elimination of unwanted cells, defense against agents of infectious disease and cancers, as well as the maintenance of tissue homeostasis (Nagata, 1997; Vaux et al, 1994). Apoptotic cell death can be triggered by the engagement of any one of several cell surface death receptors, all of which express extracellular cysteine-rich pseudorepeats, contain homologous intracellular C-terminal death domains, and are members of the TNF-receptor (TNF-R) family. These receptors include Fas, TNF-receptor 1 (TNFR1), TNF-related apoptosis-induced ligand (TRAIL)receptor 1 (R1), TRAIL-R2, DR3, and DR6 (Bazzani and Beutler, 1996; Gura, 1997; Inoue et al, 2000; Locksley et al, 2001). Stimulation of Fas and TRAIL-R1

DOI: 10.1097/01.LAB.0000079328.76631.28

Received February 28, 2003.

Supported in part by a research grant for science from the Ministry of Education, Science, and Culture of Japan.

Address reprint requests to: Dr. Katsuya Shiraki, First Department of Internal Medicine, Mie University School of Medicine, 2-174 Edobashi, Tsu, Mie 514-8507, Japan. E-mail: katsuyas@clin.medic.mie-u.ac.jp or -R2 results in clustering of the receptor, which in turn leads to recruitment of the adaptor molecule and Fas-associated death domain (FADD) and causes the receptor proximal caspase-8 to become activated upon recruitment to the death-inducing signaling complex (DISC). Active caspase-8 dissociates from DISC to start the activation of a caspase cascade, resulting in the execution phase of apoptosis (Chinnaiyan et al, 1996; Kischkel et al, 1995; Medema et al, 1997; Muzio et al, 1996; Thornberry and Lazebnik, 1998).

Recently, it has been shown that FLICE/caspase-8 inhibitory protein (FLIP), a part of DISC, is crucial for modulation of the cell death signal, inhibiting procaspase-8 processing at DISC. At first, viral proteins that contain death-effector domains were discovered in herpesvirus saimiri, human herpesvirus 8, Kaposi's sarcoma-associated herpesvirus, and molluscum contagiosum virus by screening public databases. These were named "viral FLIP" (vFLIP) (Thome et al, 1997). A human cellular homolog of vFLIP was later found and termed "cellular FLIP," (cFLIP; also called FLAME-1, I-FLICE, Casper, or CASH) (Goltsev et al, 1997; Hu et al, 1997; Irmler et al, 1997; Shu et al, 1997; Srinivasula et al, 1997). cFLIP expression af- 
fords apoptotic tolerance from known death receptors, Fas, TRAIL-R, TNFR1, and DR3 to apoptosissensitive cells (Irmler et al, 1997).

cFLIP is predominantly expressed in the heart, skeletal muscle, and peripheral blood leukocytes (Irmler et al, 1997). Hence, cFLIP is thought to be involved in the regulation of the immune system. A recent study has demonstrated that the resistance of dendritic cells against Fas-mediated apoptosis is associated with FLIP expression (Willems et al, 2000); it also showed that $B$ cell receptor signaling up-regulates FLIP and suppresses the Fas- and TRAIL-receptor apoptosis pathway, which could be important for tolerance and selection of antigen-specific B cells (Wang et al, 2000). These results suggest that cFLIP plays an important physiologic role in rescuing cells from death-receptormediated apoptosis.

Dysregulation of apoptosis signaling is often associated with disease formation, such as autoimmune diseases (Krammer, 1999) and cancer (Thompson, 1995). In hepatocarcinogenesis, failure of apoptosis is considered to be important for the survival of hepatocytes that are prone to undergo genetic damage and cellular transformation by an increased proliferative rate due to hepatocyte regeneration (SchulteHermann et al, 1997; Thorgeirsson et al, 1998). In fact, most hepatocellular carcinoma (HCC) cells show strong resistance to various stimuli that otherwise induce apoptosis. Several cellular antiapoptotic mechanisms such as reduced expression of Fas (Strand et al, 1996; Thorgeirsson et al, 1998) or caspases (Fujikawa et al, 2000), as well as expression of antiapoptotic proteins, the Bcl-2 family (Soini et al, 1996; Takehara et al, 2001), and inhibitor of apoptosis families (Ito et al, 2000; Shiraki et al, 2002), or receptor-mediated survival signals (Sugimoto et al, 1999; Suzuki et al, 2000) are known to contribute to resistance against immunologic cytotoxicity in human HCC cells. Expression of cFLIP is reported to be highly correlated with malignant potential in colonic adenocarcinomas (Ryu et al, 2001) and melanomas (Bullani et al, 2001). All of this evidence suggests that cFLIP might therefore account for the development of malignant diseases by regulating the apoptosis signaling pathway. However, the expression and biological function of cFLIP in tumor cells has not been well elucidated.

On the other hand, the transcriptional factor nuclear factor (NF)- $\kappa$ B also plays an important role in tumor cell survival. NF- $\kappa \mathrm{B}$ activation is induced by known signaling pathways, including Fas, TRAIL-R, or TNF-R1 (Ponton et al, 1996; Wajant et al, 2000). $\mathrm{NF}-\kappa \mathrm{B}$ activation induces specific gene expression to regulate programmed cell death tightly and is associated with inhibition of apoptosis (Barkett and Gilmore, 1999; Beg et al, 1995; Schmid and Adler, 2000). Attention should be called to the fact that TNF receptor families have a characteristic ability to induce two opposite effects, either apoptosis or antiapoptosis. The role of cFLIP in switching these death-receptormediated pathways has not been clarified either. Therefore, to gain insight into the biological role of cFLIP in malignant cells, we investigated the expression of cFLIP and its function in TNF family-induced apoptosis and NF- $\kappa$ B activation in human HCCs. Furthermore, we studied the regulation of cFLIP expression by several mediators.

\section{Results}

\section{Induction of Apoptosis by Anti-Fas Antibody in HCC Cells}

At first we investigated cytotoxicity of an anti-Fas agonistic antibody in HCC cells. As shown in Figure 1, anti-Fas agonistic antibody alone could not induce apoptosis in human HCC cells. Next, the effects of an RNA synthesis inhibitor, like actinomycin D (ActD), or protein synthesis inhibitor, like cycloheximide $(\mathrm{CHX})$, on anti-Fas agonistic antibody-induced apoptosis was examined. We incubated human HCC cells (SK-Hep1, HLE, or HepG2) with $0.5 \mu \mathrm{g} / \mathrm{ml} \mathrm{ActD}$ or $2.0 \mu \mathrm{g} / \mathrm{ml}$ $\mathrm{CHX}$, doses that are clinically relevant in patients, in combination with $100 \mathrm{ng} / \mathrm{ml}$ anti-Fas agonistic antibody for 24 hours at $37^{\circ} \mathrm{C}$; cell viability was also analyzed (Fig. 1). The cytotoxicity of the inhibitors alone, such as ActD, CHX, and anti-Fas agonistic antibody, was low in three HCC cell lines; however, in the presence of a subtoxic level $(0.5 \mu \mathrm{g} / \mathrm{ml}$ ActD or 2.0 $\mu \mathrm{g} / \mathrm{ml} \mathrm{CHX)}$ of metabolic inhibitors, the effect of the combination of anti-Fas agonistic antibody and these metabolic inhibitors was synergistic compared with
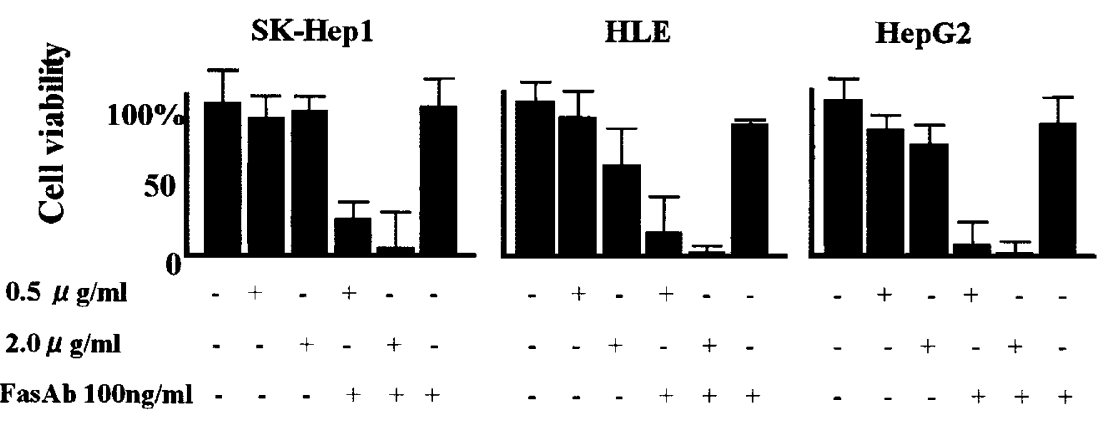

Figure 1.

The cell viability exchange of HCC cells (SK-Hep1, HLE, and HepG2) by incubation with $0.5 \mu \mathrm{g} / \mathrm{ml}$ actinomycin D, $2.0 \mu \mathrm{g} / \mathrm{ml}$ cycloheximide or $100 \mathrm{ng} / \mathrm{ml}$ anti-Fas agonistic antibody. Cell viability was assessed by the MTT assay. Data shown are the mean \pm SD of eight independent experiments. 
either agent alone in three HCC cell lines (Fig. 1). We further used DAPI staining to determine apoptosis in HCC cells by a combination of anti-Fas agonistic antibody and these metabolic inhibitors (Fig. 2). AntiFas agonistic antibody alone failed to induce nuclear fragmentation or condensation (Fig. 2A). Nuclear morphologic exchanges were also not detected in ActD or $\mathrm{CHX}$ alone (data not shown); however, the combination of $100 \mathrm{ng} / \mathrm{ml}$ anti-Fas agonistic antibody and 0.5 $\mu \mathrm{g} / \mathrm{ml}$ ActD or $2.0 \mu \mathrm{g} / \mathrm{ml} \mathrm{CHX}$ showed typical apoptotic features (Fig. 2, B and C). These results showed that subtoxic levels of ActD or $\mathrm{CHX}$ could nullify resistance to Fas-induced apoptosis in these HCC cells.

\section{Pro-caspase-8 and -3 Cleavage by Anti-Fas Agonistic Antibody-Induced Apoptosis}

We speculated that apoptosis induction by the combination of anti-Fas agonistic antibody and metabolic inhibitors followed a cascade of caspase activation. To assess the caspase activity with respect to this apoptosis induction and to determine at what point HCC cell lines inhibit Fas-induced caspase cascade, we examined the expression of pro-caspase- 8 and pro-caspase-3 (Fig. 3). Although anti-Fas agonistic antibody alone did not show a change of procaspase- 8 and -3 expression levels, a combination of anti-Fas agonistic antibody and ActD or CHX simultaneously showed down-regulation of both procaspase-8 and -3 protein expression levels.

\section{cFLIP Protein Expression in Human HCC Tissues and Cells}

We showed that a combination of anti-Fas agonistic antibody and metabolic inhibitors induced both caspase- 8 and caspase- 3 activation in HCC cell lines (Fig. 3). This result suggests that apoptotic signal inhibition may exist upstream of caspase-8 and impli- a)

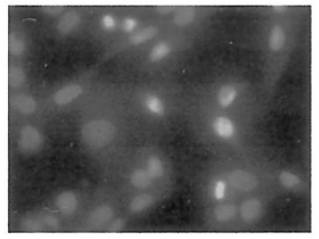

c)

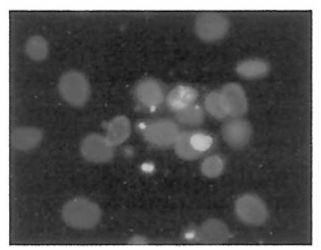

b)

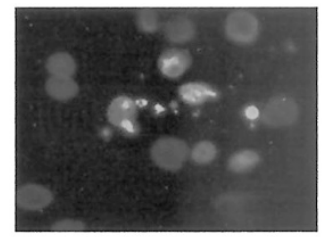

Figure 2.

DAPI (4'6-diamidino-2-phenylindol) staining of hepatocellular carcinoma (HCC) cells. (A) HCC cells (HLE) were incubated with $100 \mathrm{ng} / \mathrm{ml}$ anti-Fas antibody. (B) Cells were incubated with $100 \mathrm{ng} / \mathrm{ml}$ anti-Fas agonistic antibody and $0.5 \mu \mathrm{g} / \mathrm{ml}$ actinomycin D (ActD). (C) Cells were incubated with $100 \mathrm{ng} / \mathrm{ml}$ anti-Fas agonistic antibody and $2.0 \mu \mathrm{g} / \mathrm{ml}$ cycloheximide (CHX). Co-incubation of anti-Fas agonistic antibody and ActD or CHX demonstrated typical apoptotic features, including nuclear condensation and nuclear fragmentation. cates cFLIP, which is an anti-apoptotic protein. To determine in situ expression of cFLIP, 20 human HCC tissues and 20 nontumor hepatic tissues were examined for cFLIP protein expression by immunohistochemistry (Fig. 4, A and B). Although both HCC and nontumor preparations showed the expression of cFLIP in their cytoplasmic area, staining was stronger in HCC than in nontumor hepatic cells. There was a statistically significant difference in cytoplasmic staining intensity between HCC and nontumor cells (Fig. 4C). There was no nuclear stain in either cell type.

Next we investigated the expression of cFLIP protein in seven HCC cells (HepG2, SK-Hep1, HLE, Hep3B, Huh7, Chang liver, and PLC/PRF/5). As shown in Figure 5, the expression of 55-kd cFLIP protein was detected in all seven HCC cells and Jurkat cells. Although we investigated the expression of cFLIPs, cFLIPs protein was not detected in all seven HCC cells (data not shown). Three HCC cell lines, including HepG2, SK-Hep1, and HLE, expressed higher levels of cFLIP than the other HCC cells. We also analyzed cFLIP protein expression in HCC cells (HepG2, SKHep1, and HLE), which were incubated with subtoxic levels of ActD $(0.5 \mu \mathrm{M})$ or $\mathrm{CHX}(2.0 \mu \mathrm{M})$ for 24 hours. In this experiment it was seen that cFLIP expression decreased in HCC cells (Fig. 6).

\section{cFLIP Down-Regulation Sensitized HCC Cells to Fas-Mediated Apoptosis}

The observation that cFLIP protein is down-regulated by subtoxic levels of ActD or $\mathrm{CHX}$ and that apoptosis is induced by a combination of anti-Fas antibody and metabolic inhibitors suggests the importance of cFLIP in apoptotic inhibition. To evaluate the role of cFLIP protein in apoptosis in HCC cells, we made a cFLIP antisense oligodeoxynucleotide and transfected it in HLE cells. As shown in Figure 7A, cFLIP protein expression showed down-regulation after transfection of cFLIP antisense oligodeoxynucleotide, but cFLIP sense oligodeoxynucleotide did not affect the expression level of cFLIP. Pro-caspase-8 and -3 expression did not change upon cFLIP sense or antisense oligodeoxynucleotide transfection (data not shown).

Next, to assess the effect of cFLIP down-regulation by cFLIP antisense transfection on death-receptor stimulation in HLE cells, we analyzed cell viability. Under conditions of down-regulation of cFLIP expression, death-receptor stimulation (including anti-Fas agonistic antibody, TNF- $\alpha$, or TRAIL) caused a decrease of cell viability compared with anti-Fas agonistic antibody, TNF- $\alpha$, or TRAIL alone (Fig. 7B). In contrast, cell viability with cFLIP sense transfection was not affected by these stimulators.

\section{cFLIP-Regulated TNF- $\alpha$ or TRAIL-Induced NF-кB Activation in HCC Cells}

Human HCC cells showed strong resistance to TRAILmediated apoptosis and TRAIL-induced NF- $\kappa$ B activation in $\mathrm{HCC}$ cells in a dose-dependent manner (Yamanaka et al, 2000). However, the role of cFLIP in 
Pro-Caspase-8

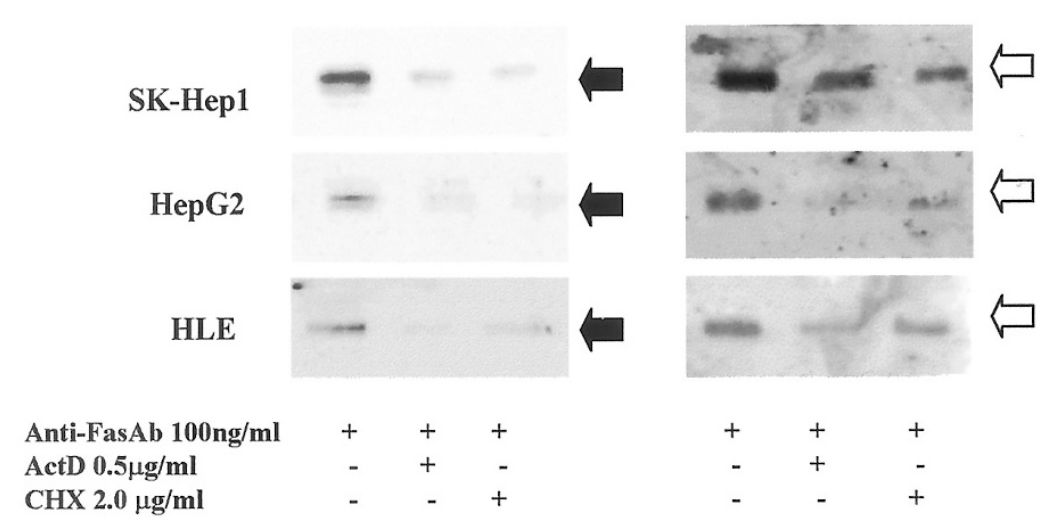

Figure 3.

Expression of pro-caspase-8 (55 kd) and -3 (32 kd) determined by Western blotting. For 24 hours, $2 \times 10^{5}$ hepatocellular carcinoma (SK-Hep1, HLE, and HepG2) cells were cultured in a $60-\mathrm{mm}$ dish, followed by addition of $0.5 \mu \mathrm{g} / \mathrm{ml}$ actinomycin D (ActD) or $2.0 \mu \mathrm{g} / \mathrm{ml}$ cycloheximide (CHX) and $100 \mathrm{ng} / \mathrm{ml}$ anti-Fas agonistic antibody for 18 hours. Closed arrows indicate the expression of pro-caspase-8; opened arrows indicate pro-caspase-3.

a)

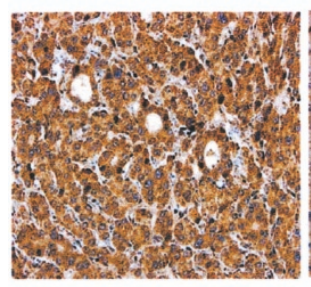

b)

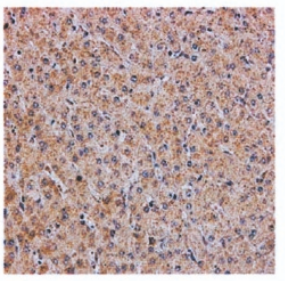

c)

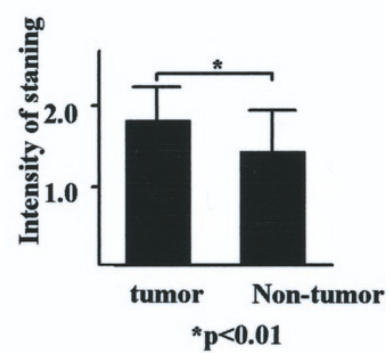

Figure 4.

Indirect immunohistochemical staining of human HCC (A) or nontumor hepatic cells (B) with cellular FLICE/caspase-8-inhibitory protein (cFLIP). Both preparations were stained with antibody for cFLIP and counterstained with hematoxylin $(\times 200)$. (C) Comparison of intensity of staining between resected human hepatocellular carcinoma (HCC) tissue and non-HCC tissue. Data shown are the mean \pm SD of 25 independent experiments. The Chi-square test was used to compare the staining intensity of $\mathrm{HCC}$ and nontumor hepatic cells. $p<0.05$ was regarded as statistically significant.

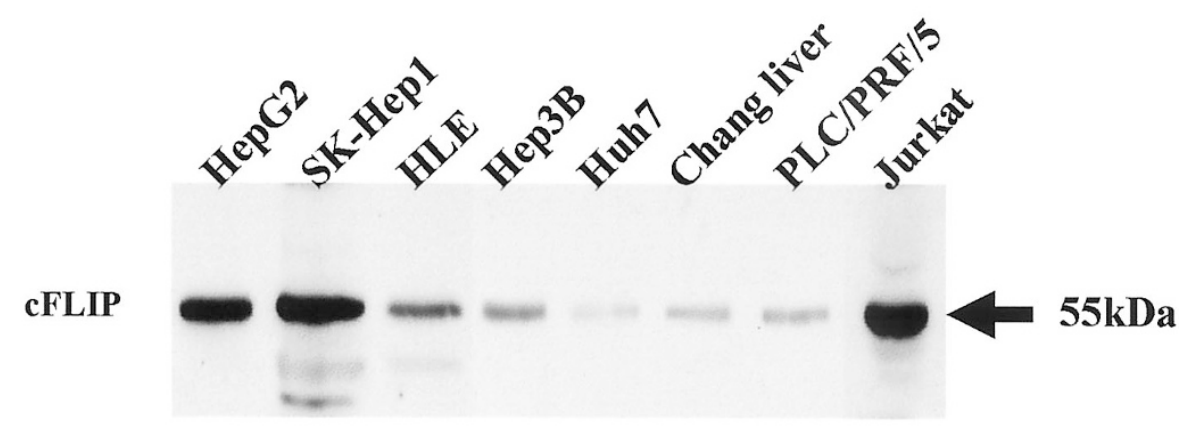

Figure 5.

Cellular FLICE/caspase-8-inhibitory protein (cFLIP) expression in seven human hepatocellular carcinoma cell lines (HepG2, HLE, SK-Hep1, Hep3B, Huh7, Chang liver, and PLC/PRF/5) and a human T cell lymphoma cell line (Jurkat) by Western blotting. Arrow indicates the expression of cFLIP (55 kd).

death-receptor-induced NF- $\kappa$ B activation in $\mathrm{HCC}$ cells is not clear. At first, we analyzed the NF- $\kappa \mathrm{B}$ activation level of HCC cells with TNF- $\alpha$ or TRAIL stimulation under conditions of cFLIP up-regulation. HCC cells showed an increase of cFLIP expression level with cFLIP expression vector transfection, compared with a mock transfection (Fig. 8A). HCC cells with CFLIP up-regulation were stimulated with 50 $\mathrm{ng} / \mathrm{ml}$ TNF- $\alpha$ or $50 \mathrm{ng} / \mathrm{ml}$ TRAlL for 12 hours. As shown in Figure $8 \mathrm{~B}$, we confirmed that NF- $\kappa \mathrm{B}$ activity induced by TNF- $\alpha$ or TRAIL in these HCC cells substantially increased under CFLIP up-regulation.

cFLIP inhibits caspase activity by interfering with pro-caspase-8 cleavage, which is the starting point of the caspase-cascade and inhibits apoptosis (Irmler et al, 1997). We next investigated the effect on NF- $\kappa$ B 


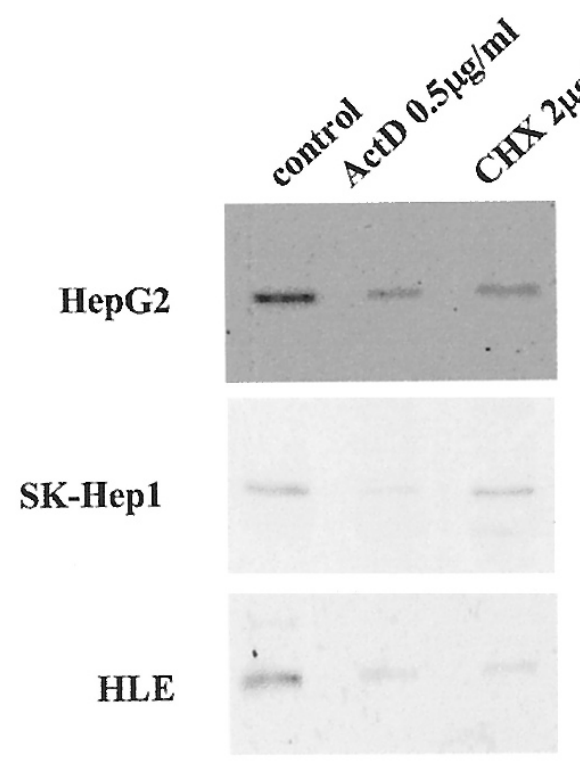

Figure 6.

Cellular FLICE/caspase-8-inhibitory protein (CFLIP) expression in hepatocellular carcinoma cells (SK-Hep1, HLE, and HepG2) after incubation with 0.5 $\mu \mathrm{g} / \mathrm{ml}$ ActD or $2.0 \mu \mathrm{g} / \mathrm{ml} \mathrm{CHX}$ for 24 hours. The cFLIP expression was analyzed by Western blotting.

a)

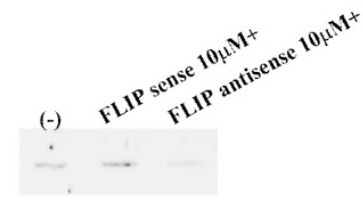

b)

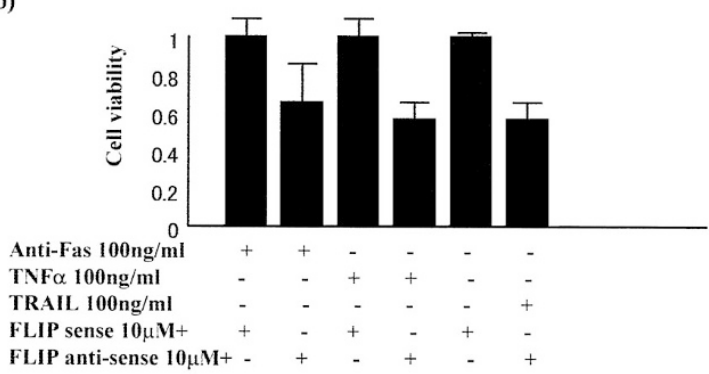

Figure 7.

(A) The down-regulation of cellular FLICE/caspase-8-inhibitory protein (cFLIP) expression in HLE cells after transfection of CFLIP antisense oligodeoxynucleotides. CFLIP sense oligodeoxynucleotides transfection did not affect cFLIP expression level. Hepatocellular carcinoma cells were transfected with $10 \mu \mathrm{m}$ cFLIP sense or antisense oligodeoxynucleotides and incubated for 24 hours at $37 \mathrm{C}^{\circ}$. (B) Cell viability decreased on incubation with $100 \mathrm{ng} / \mathrm{ml}$ anti-Fas agonistic antibody, $100 \mathrm{ng} / \mathrm{ml}$ TNF- $\alpha$, or $100 \mathrm{ng} / \mathrm{ml}$ TNF-related apoptosisinduced ligand (TRAIL) after CFLIP antisense oligodeoxynucleotides transfection in HLE cells. cFLIP sense oligodeoxynucleotides transfection did not affect cell viability with anti-Fas agonistic antibody, TNF- $\alpha$, or TRAIL incubation. Cell viability was assessed by MTT assay. Data shown are the mean \pm SD of five independent experiments.

activation by pan-caspase-inhibitor, Z-VAD-fmk pretreatment with cFLIP down-regulation by cFLIP antisense oligodeoxynucleotides transfection. Pretreatment with $40 \mu \mathrm{M}$ Z-VAD-fmk further increased TNF- $\alpha$ or TRAIL-induced NF- $\kappa$ B activation (Fig. 9A). In contrast to induction of NF- $\kappa B$ activation by cFLIP up- regulation, FLIP down-regulation attenuated the effect of TNF- $\alpha$ or TRAIL-induced NF- $\kappa$ B activation (Fig. 9B). However, NF- $\kappa$ B activation was restored by Z-VADfmk addition, though cFLIP protein was downregulated (Fig. 9B). In these experiments cell viabilities did not change (data not shown).

\section{cFLIP Protein Expression is Regulated through NF-кB Activation or PI-3/Akt Kinase Pathway in HCC Cells}

Finally, we investigated cFLIP expression exchange in $\mathrm{HCC}$ cells by NF- $\kappa \mathrm{B}$ or PI-3/Akt kinase pathway stimulation. Stimulation with $50 \mathrm{ng} / \mathrm{ml}$ TNF- $\alpha$ or TRAIL, which has already been shown to activate NF- $\kappa$ B, showed up-regulation of cFLIP in HLE cells (Fig. 10). The up-regulation of cFLIP in HLE cells was also observed after $100 \mathrm{ng} / \mathrm{ml}$ vascular endothelial growth factor (VEGF) stimulation (Fig. 10). However, treatment with $200 \mathrm{~nm}$ wortmannin, which inhibits the Pl-3/Akt kinase pathway, showed a down-regulation pf cFLIP in HLE cells (Fig. 10). These reagents did not affect cell viability (data not shown). Hence, it is implicated that cFLIP expression level is regulated through the NF- $\kappa \mathrm{B}$ or PI-3/Akt kinase pathways in HCC cells.

\section{Discussion}

TNF receptor family-mediated apoptosis in a variety of human cells plays an important role in the host's defense against tumor cells via $T$ lymphocytes or macrophages. These receptors contain intracellular regions called "death domains," which convert direct receptor-triggered signaling into apoptosis (Nagata, 1997). To escape the host's immune response, it is necessary for tumor cells to be more resistant to this TNF family-induced apoptosis. In fact, most HCC cells show strong resistance to Fas (Fulda et al, 2000; Natoli et al, 1995) and TRAIL receptor-mediated apoptosis (Yamanaka et al, 2000), and have several mechanisms, such as down-regulation of death-signaling component (Fujikawa et al, 2000; Strand et al, 1996) or expression of antiapoptotic proteins (Ito et al, 2000; Shiraki et al, 2002; Soini et al, 1996; Takehara et al, 2001).

The current study demonstrated that the resistance of HCC cells to Fas-mediated apoptosis can be overcome by a subtoxic level of ActD that inhibits messenger RNA transcription and $\mathrm{CHX}$ that inhibits protein synthesis. The same results were obtained in TRAILR-mediated apoptosis (Yamanaka et al, 2000). These data suggest that resistance to apoptosis was more likely mediated by intracellular signaling events than by alternation in receptor expression or the presence of decoy receptors and that the components including cFLIP of Fas-mediated apoptosis exist in these HCC cells. Then it becomes crucial to determine the critical endogenous suppressors of Fas-mediated apoptosis that are sensitive to those metabolic inhibitors.

To address these questions, it is important to determine at which level HCC cells inhibit TNF familyinduced death signaling. First, we have examined processing of the most upstream protease, 

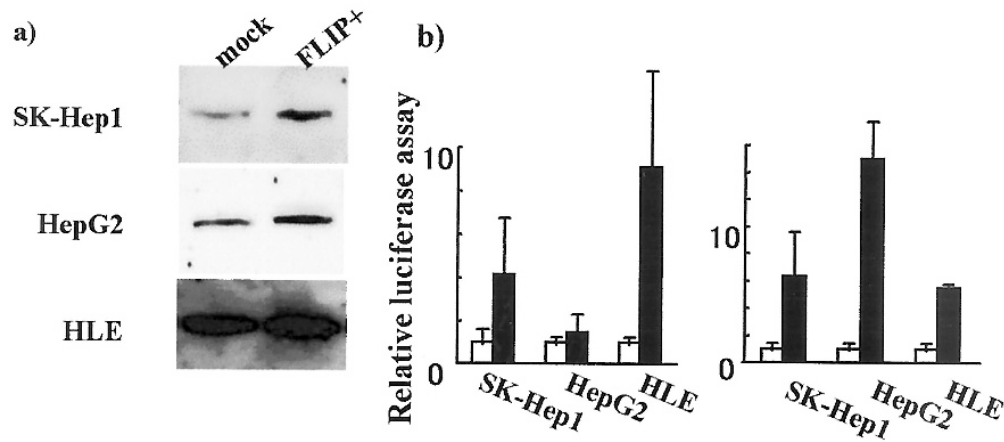

TNF $\alpha 50 \mathrm{ng} / \mathrm{mI}$

TRAIL50ng/ml

Figure 8.

(A) The up-regulation of cellular FLICE/caspase-8-inhibitory protein (CFLIP) expression by cFLIP expression vector transfection in HLE cells. For 24 hours $2 \times 10^{5}$ HCC cells were grown in a $60-\mathrm{mm}$ dish at $37^{\circ} \mathrm{C}$ the day before transfection. The CFLIP expression vector or mock vector was transfected using FuGENE 6 for 24 hours at $37^{\circ} \mathrm{C}$. Western blotting showed an increase of CFLIP expression in CFLIP expression vector transfected cells, more than in control vector transfected cells (B) Effects of cFLIP up-regulation on NF- $\kappa$ B activation with TNF- $\alpha$ or TNF-related apoptosis-induced ligand (TRAIL) treatment in hepatocellular carcinoma (HCC) cells. Open bars show NF- $\kappa$ B activation with mock-transfected cells, and closed bars show NF- $\kappa$ B activation with cFLIP expression vector-transfected cells. The pNF- $\kappa$ B-Luc Vector and cFLIP expression vector or mock vector were co-transfected in human HCC cells. After incubation for 24 hours at $37 \mathrm{C}^{\circ}$, cells were stimulated by $50 \mathrm{ng} / \mathrm{ml}$ TNF- $\alpha$ or $50 \mathrm{ng} / \mathrm{ml}$ TRAIL for 12 hours. NF- $\kappa B$ activation was assessed by luciferase assay system. Data shown are the mean \pm SD of three independent experiments.

caspase-8, and a critical down-stream protease, caspase-3, in the protease cascade, when Fas receptor was stimulated in the presence or absence of the metabolic inhibitors. Our results show that caspase-8 was not activated by cleavage, and in addition caspase-3 was not cleaved when treated with anti-Fas agonistic antibody either. However, both caspases were significantly processed in the presence of the metabolic inhibitors when treated with anti-Fas agonistic antibody. These results indicate that the Fasmediated death signal was inhibited at the caspase-8 level, and inhibitors of caspase- 8 may play a critical role in resistance to death-receptor-mediated apoptosis. We have obtained similar results, which indicate that TRAIL-R-mediated apoptosis is also inhibited at both caspase- 8 and caspase- 3 levels (Yamanaka et al, 2000).

cFLIP contains tandem death-effector domains and caspase-like domain similar to procaspase- 8 but lacks amino acid residues that are critical for caspase activity, most notably the cysteine in the catalytic center (Irmler et al, 1997). cFLIP suppresses all known receptor-mediated apoptosis by inhibiting procaspase-8 processing (Irmler et al, 1997). Surprisingly, some viruses encoded the homolog of cFLIP, which also controls sensitivity toward death-receptormediated apoptosis (Thome et al, 1997). Also, cFLIPdeficient mice do not survive past Day 10.5 of embryogenesis and exhibit impaired heart development (Yeh et al, 2000). These findings also suggested that cFLIP has a crucial role in regulation of cell death and a potential role in malignant transformation. Therefore, we have investigated the expression and function of caspase-8 inhibitor, cFLIP, in HCC cells.

Our study shows that cFLIPs are constitutively expressed in all HCC cell lines examined and that the expression level of cFLIP depended on the individual cell type. During apoptosis induced by anti-Fas agonistic antibody in the presence of metabolic inhibitors, cFLIP was significantly down-regulated, indicating that CFLIP was one of the sensitive targets of protein synthesis inhibitors for the sensitization of apoptosis.

We then investigated the antiapoptotic function of cFLIP in HCC cells. Experiments using cFLIP antisense oligonucleotides revealed that specific downregulation of cFLIP sensitized about $30 \%$ to $50 \%$ of HLE cells to all Fas, TNF-R, and TRAIL-R-mediated apoptosis. These results support the crucial role of cFLIP in death-receptor-mediated apoptosis and also other antiapoptotic mechanisms that exist in HCC cells. In fact, inhibitors of apoptosis family or $\mathrm{Bcl}$ family are also important apoptotic inhibitors overexpressed in HCC cells (Takehara et al, 2001). A recent study revealed that the relative levels of caspase- 8 and CFLIP are an important determinant of susceptibility to Fas-mediated apoptosis in malignant cells (Krueger et al, 2001; Tepper and Seldin, 1999), although it is not clear what amounts of cFLIP are required to protect cells from apoptosis. It is likely that high levels of cFLIP might contribute to antiapoptotic function.

In human HCC tissues, cFLIP was expressed significantly stronger in HCC cells than surrounding nontumor tissues. In colonic adenocarcinomas, cFLIP is frequently elevated at both mRNA level and protein level (Ryu et al, 2001), and is also strongly expressed in $83 \%$ of melanomas (Bullani et al, 2001), although it is not expressed in most benign melanocytic lesions. In human melanoma cells, the expression level of cFLIP correlated with resistance to TRAIL-induced apoptosis (Griffith and Lynch, 1998). Furthermore, overexpression of cFLIP by transfection in a Fas- and TRAIL-sensitive human melanoma cell line rendered this cell line more resistant to stimulation by both FasL and TRAIL (Bullani et al, 2001). This also suggests that cell-death inhibition by cFLIP overexpression might be the fundamental mechanism of cell-death regulation in malignant transformed cells. It has also been reported that VFLIP and cFLIP mediate the immune escape of tumors (Djerbi et al, 1999; Medema et al, 1999). A 
a)

\section{Z-VAD-fmk 40 $\mu M$ \\ TNF $\alpha$ 50ng/ml TRAIL 50ng/ml}

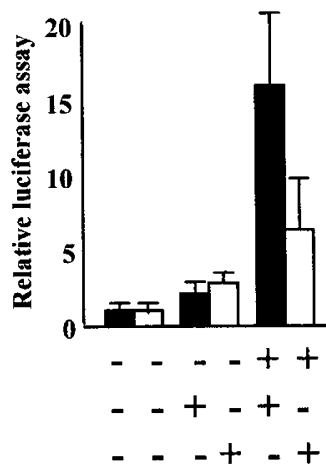

b)

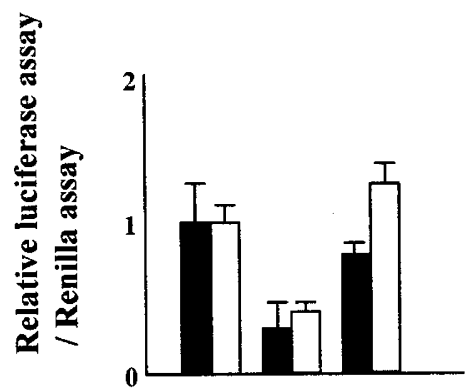

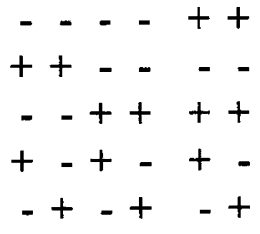

Figure 9.

Effects of Z-VAD-fmk treatment or cellular FLICE/caspase-8-inhibitory protein (cFLIP) down-regulation by $10 \mu \mathrm{M}$ CFLIP antisense oligodeoxynucleotides transfection on NF- $\kappa$ B activation with TNF- $\alpha$ or TNF-related apoptosis-induced ligand (TRAIL) stimulation in HLE cells. Closed bars show $50 \mathrm{ng} / \mathrm{ml}$ TNF- $\alpha$ stimulation, and open bars show $50 \mathrm{ng} / \mathrm{ml}$ TRAIL stimulation. The shown data are the mean \pm SD of three independent experiments. (A) HLE cells were pretreated with $40 \mu \mathrm{m}$ Z-VAD-fmk for 1 hour before treatment with TNF- $\alpha$ or TRAIL. Reporter gene activity was measured 12 hours after treatment. Z-VAD-fmk treatment increased NF- $\kappa$ B activation by TNF- $\alpha$ or TRAIL stimulation more than TNF- $\alpha$ or TRAIL alone. (B) The pNF- $\kappa$ B-Luc Vector and $10 \mu \mathrm{m}$ cFLIP antisense or sense oligodeoxynucleotides were co-transfected in HLE cells. After incubation for 24 hours at $37 \mathrm{C}^{\circ}$, cells were stimulated by $50 \mathrm{ng} / \mathrm{ml}$ TNF- $\alpha$ alone or $50 \mathrm{ng} / \mathrm{ml}$ TNF- $\alpha$ with $40 \mu \mathrm{M}$ Z-VAD-fmk for 1 hour pretreatment. TRAIL was also used under the same conditions. Reporter gene assay was measured after 4 hours of TNF- $\alpha$ or TRAIL treatment. CFLIP downregulation attenuated NF- $\kappa B$ activation by TNF- $\alpha$ or TRAIL stimulation. The effects of cFLIP down-regulation were restored with $40 \mu \mathrm{M}$ Z-VAD-fmk incubation.

recent study has demonstrated that, using in vivo murine tumor models, cFLIP does help in escape from $T$ cell immunity and that tumor cells are selected for elevated cFLIP expression (Medema et al, 1999). Thus, we hypothesized that human HCC cells with elevated cFLIP expression might also be selected for survival, most likely due to immunological pressure exerted by the host during carcinogenesis and tumor development.

$\mathrm{NF}-\kappa \mathrm{B}$ is a transcription factor that prevents cell death and promotes cell survival, regulating several

$(-)$

(+)

\section{TNF $\alpha 50 \mathrm{ng} / \mathrm{ml}$}

TRAIL50ng/mI

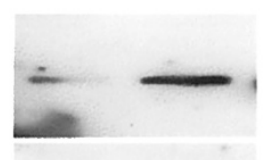

VEGF100ng/ml

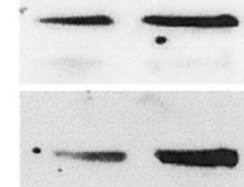

\section{Wortmannin200nM}

\section{Figure 10.}

Effects of TNF- $\alpha$, TNF-related apoptosis-induced ligand (TRAIL), vascular endothelial growth factor (VEGF), or wortmannin (WM) treatment on cellular FLICE/caspase-8-inhibitory protein (cFLIP) expression in HLE cells. HLE cells were incubated with these reagents $(50 \mathrm{ng} / \mathrm{ml} \mathrm{TNF}-\alpha, 50 \mathrm{ng} / \mathrm{ml}$ TRAIL, 100 $\mathrm{ng} / \mathrm{ml}$ VEGF, or $200 \mathrm{~nm}$ WM) for 24 hours and analyzed by Western blotting. These results showed that cFLIP expression was up-regulated by TNF- $\alpha$, TRAIL, or VEGF treatment and down-regulated by WM.

gene encoding proteins such as cellular inhibitor of apoptosis (Wang et al, 1998), TNF-R associated factor 1 (TRAF1) (Wang et al, 1998), and Bcl-xL (Khoshnan et al, 2000).

$\mathrm{NF}-\kappa \mathrm{B}$ is known to be activated by receptor signals such as TNF-R1, TRAIL-R1, TRAIL-R2 (Ponton et al, 1996; Wajant et al, 2000), IL-1 $\beta$ (Barnes and Karin, 1997), or IL-18 (Robinson et al, 1997). The deathdomain-containing receptors TNF-R1, TRAIL-R1, and -R2 are capable of initiating apoptosis but also have gene-induced property via NF- $\kappa \mathrm{B}$. We have recently demonstrated that TRAIL-R1 and -R2 expression was prevalent and that TRAIL activated NF- $\kappa$ B rather than induced apoptosis in HCC cells (Yamanaka et al, 2000). These pieces of evidence suggested that HCC cells use TRAIL signaling as their cell survival signal. Then it becomes important to elucidate how these transformed cells regulate the death-receptor-mediated signaling to survive.

In this study we have demonstrated that cFLIP overexpression or pan-caspase-inhibitor, Z-VAD-fmk, accelerated NF- $\kappa$ B activation induced by TNF-R or TRAIL-R stimulation. In addition, cFLIP suppression by antisense oligonucleotides attenuated the NF- $\kappa$ B activation. These results imply that cFLIP protein plays the important role of an endogenous signaling pathway switching modulator to either apoptosis induction or cell proliferation. It has been reported that cFLIP interacts with TRAF1 and TRAF2, as well as with the receptor interacting protein (RIP), resulting in NF- $\kappa \mathrm{B}$ activation in Jurkat cells (Kataoka et al, 2000). In addition, a recent study showed that caspasemediated cleavage of RIP inhibits its capacity to activate NF- $\kappa \mathrm{B}$ (Harper et al, 2001) and that cFLIP may prevent RIP cleavage by inhibiting these caspases and enhance NF- $\kappa$ B. Our study clearly demonstrates that 
$\mathrm{NF}-\kappa \mathrm{B}$ activation was restored by Z-VAD-fmk even when CFLIP is down-regulated. This will also support the previous findings. In contrast to our study, there is a report that the overexpression of cFLIP inhibits death-receptor-mediated NF- $\kappa \mathrm{B}$ activation in HeLa cells (Wajant et al, 2000). These differences may be due to cell types or other possible candidates that can be part of the receptor-signaling complex of death receptors. Further study will be needed to show how cFLIP regulates NF- $\kappa$ B activation. In this study, we provide evidence to show that cFLIP is not simply an inhibitor of death-receptor-mediated apoptosis, but it also mediates the activation of $\mathrm{NF}-\kappa \mathrm{B}$, which promotes cell survival in HCC.

How is cFLIP expression regulated in HCC cells? Our study shows that either NF- $\kappa \mathrm{B}$ or PI-3/Akt kinase activation can induce FLIP protein up-regulation and $\mathrm{PI}-3 /$ Akt kinase inhibition can induce FLIP protein down-regulation in HLE cells. NF- $\kappa \mathrm{B}$ or PI-3/Akt kinase are associated with the regulation of expression of many genes and play an important role in oncogenesis or tumor cell growth (Rayet and Gelinas, 1999; Shi et al, 2002). Furthermore, metabolic inhibitors acting on either transcription or translation were shown to abolish cFLIP expression. Our results support previous findings concerning cFLIP regulation using other transformed cell lines. In addition, autocrine regulation of cFLIP may exist, because HCC cells strongly expresses VEGF (Chow et al, 1997; Yamaguchi et al, 1998) by themselves. Furthermore, immunological cytotoxicity of lymphocytes by the TNF family may contribute to cFLIP up-regulation, because TNFreceptor families including TNF-R1 and $-\mathrm{R} 2$, and TRAIL-R1, -R2, -R3, or -R4 have signaling pathways that involve NF- $\kappa \mathrm{B}$ activation (Bernard et al, 2001; Degli-Esposti et al, 1997; Ponton et al, 1996; Seitz et al, 2001; Wajant et al, 2000). The pieces of evidence indicate that cFLIP regulation is tightly controlled by many factors both endogenously and exogenously.

In conclusion we have demonstrated that cFLIP is not simply an inhibitor of death-receptor-mediated apoptosis but that it also induced NF- $\kappa$ B activation. These results indicate that cFLIP plays an important role in controlling cell death or survival and switching signals to either a caspase cascade or NF- $\kappa$ B. Our study implies that a strategy to inhibit cFLIP expression may be a potential tool in the useful treatment of human HCCs.

\section{Materials and Methods}

\section{Cell Lines and Human HCC Tissues}

The Jurkat $T$ cell line, the human HCC cell lines, HepG2, Hep3B, and SK-Hep1 cells were purchased from American Type Culture Collection (Rockville, Maryland). The HCC cell lines, Huh7, HLE, and PLC/ PRF/5 were all purchased from the Health Science Research Resource Bank (Osaka, Japan). The Jurkat cells were cultured in RPM1 1640 (Gibco BRL, Grand Island, New York). The other cell lines were cultured in Dulbecco's modified Eagle medium (Dainippon Phar- maceutical Company, Ltd., Osaka, Japan). All media were supplemented with $1 \%$ penicillin/streptomycin (Gibco BRL) and 10\% heat-inactivated FCS (Gibco $\mathrm{BRL}$ ). Human $\mathrm{HCC}$ tissues and nontumor tissues were obtained from surgical resection for immunohistochemical analysis. We obtained informed consent from patients for subsequent use of their resected tissues.

\section{Assessment of Viability of HCC Cells}

To assess the viability of HCC cells, the 3-(4,5dimethylthiazol-2-yl)-2,5-diphenyl tetrazolium bromide (MTT) assay was performed. The HCC cells were plated at a density of $5 \times 10^{3}$ cells/well in 96 well microtiter plates (Corning Glass Works, Corning, New York). Either $0.5 \mu \mathrm{g} / \mathrm{mL}$ ActD (Sigma Chemical Company, St. Louis, Missouri) or $2.0 \mu \mathrm{g} / \mathrm{mL}$ CHX (Sigma) was added in the absence or presence of $100 \mathrm{ng} / \mathrm{ml}$ anti-Fas agonistic antibody (MBL, Nagoya, Japan), and the plate was incubated for 24 hours, respectively. The live-cell count was determined using a Cell Titer 96 assay kit (Promega, Madison, Wisconsin) according to the manufacturer's instructions. The absorbance of each well was measured at $570 \mathrm{~nm}$ with a microtiter plate reader (Bio-Rad Laboratories, Hercules, California).

\section{Detection of Apoptosis}

For 24 hours $2 \times 10^{4} \mathrm{HCC}$ cells/well were cultured in an 8-well Lab-tek II chamber slide (NUNC ${ }^{\mathrm{TM}}$ Brand Products, Demmark), followed by the addition of 0.5 $\mu \mathrm{g} / \mathrm{mL}$ ActD (Sigma) or $2.0 \mu \mathrm{g} / \mathrm{mL}$ CHX (Sigma) and $100 \mathrm{ng} / \mathrm{ml}$ anti-Fas agonistic antibody (MBL). After a further incubation for 24 hours, cell nuclei were stained with 4'6-diamidino-2-phenylindole (DAPI) (Sigma) and observed with a fluorescence microscope (Zeiss, Göttingen, Germany).

\section{Western Blotting}

Expression of pro-caspase-8 and -3, cFLIPL, and cFLIPs were analyzed by Western blotting. Anticaspase-8 was purchased from Upstate Biotechnology (Lake Placid, New York). Caspase-3 p20 was purchased from Santa Cruz Biotechnology, Inc. (Santa Cruz, California). These antibodies did not detect active forms of caspase-8 or caspase-3. Anti-FLIP polyclonal antibody was purchased from Millennium Biotechnology (Romona, California). Anti-FLIPs $(\gamma / \delta)$ were purchased from Calbiochem (Darmstadt, Germany). HCC cells were harvested and lysed in lysis buffer $(50 \mathrm{mmol} / \mathrm{L}$ Tris-HCl, $8 \mathrm{pH}, 150$ mmol/L NaCl, 5 $\mathrm{mmol} / \mathrm{L}$ ethylenediaminetetraacetic acid, 1\% NP-40, 1 $\mathrm{mmol} / \mathrm{L}$ phenylmethylsulfonyl fluoride) on ice. Protein contents measured using a Bio-Rad Protein Assay Kit (Bio-Rad Laboratories). Equal amounts of protein from each extract were separated by $14 \%$ sodium dodecyl sulfate-polyacrylamide gel electrophoresis (SDSPAGE) and transferred onto nitrocellulose membranes (Toyo Roshi, Tokyo, Japan). Blots were blocked by incubation in 5\% nonfat dried milk in Tris buffered 
saline overnight at $4^{\circ} \mathrm{C}$ and probed for 2 hours at room temperature with primary antibody. The immunoblots were then probed with horseradish peroxidase-conjugated Ig G (1:2000 diluted with 5\% nonfat dried milk in Tris- $\mathrm{HCl} ; 7.5 \mathrm{pH}$ and $0.05 \%$ Tween 20). Signal was detected with an ECL kit (Amersham Pharmacia Biotech, Buckinghamshire, United Kingdom).

\section{Immunohistochemical Staining for cFLIP Protein}

Immunohistochemical staining for cFLIP protein was performed on resected HCC tissues and nontumor tissues. Deparaffinized sections were heated for 10 minutes at $120^{\circ} \mathrm{C}$ in a pressure cooker to reactivate antigen and treated with $0.3 \% \mathrm{H}_{2} \mathrm{O}_{2}$ in methanol for 20 minutes to abolish endogenous peroxidase activity. Sections were blocked with normal goat serum in PBS (PBS) and incubated overnight with a 1:40 dilution (in PBS) of anti-cFLIP polyclonal antibody at $4^{\circ} \mathrm{C}$. The sections were incubated with a second biotinylated antirabbit Ig diluted 1:200 in PBS, followed by a 1:200 dilution of avidin-biotin-peroxidase complex (Vectastain ABC kit; Vector Laboratories, Burlingame, California) diluted 1:200 in PBS for 30 minutes at room temperature. They were developed in a substrate solution of $0.01 \% 3,3^{\prime}$ - diaminobenzidine-hydrogen peroxide for visualization and counterstained with Mayer's hematoxylin. The stained sections were examined under $\times 200$ magnification. The immunostaining was analyzed semiquantitatively using a scoring system: 1 was defined as weak staining intensity, 2 was defined as moderate staining intensity, and 3 was defined as strong staining intensity. The results presented for each tissue are representative of immunohistochemical analysis of multiple immunostained slides.

\section{cFLIP Antisense Oligodeoxynucleotides or cFLIP Expression Vector Transfection in HCC Cells}

To inhibit cFLIP protein expression in HCC cells, phosphorothiorate antisense oligodeoxynucleotides to inhibit the cFLIP initiation codons and control sense oligodeoxynucleotides with the following published sequences were used (Perlman et al, 1999): cFLIP antisense, 5'-gatttcagcagacatcctac-3'; and cFLIP sense, 5'-catcctacagacgacttcag-3'. Using FuGENE 6 system (Boehringer Mannheim, Mannheim, Germany), $1 \times 10^{5} \mathrm{HCC}$ cells/well were transfected with $10 \mu \mathrm{m}$ cFLIP antisense or sense oligodeoxynucleotides according to the manufacture's protocol.

The cFLIP expression vector was a gift from Dr. Valentina Screpanti (Department of Immunology, University of Stockholm, Sweden). The cFLIP expression vector was transfected using FuGENE 6 (Boehringer Mannheim), essentially according to the manufacture's protocol, for 24 hours at $37^{\circ} \mathrm{C}$. As a mock vector, pcDNA3.1 (-)/Myc-His (Invitrogen, Carlsbad, California) was used. This vector was transfected using similar conditions of cFLIP transfection. Expres- sion of cFLIP protein was analyzed by Western blotting.

\section{NF-кB Luciferase Reporter Gene Assay}

The pNF- $\kappa$ B-Luc Vector (Mercury Pathway Profiling System) was obtained from Clontech (San Diego, California). Using FuGENE 6 (Boehringer Mannheim), 2 $\times 10^{5}$ human $\mathrm{HCC}$ cells were transfected according to the manufacturer's protocol. Luciferase activity was determined from cell extracts by means of a luciferase assay system (Promega) and luminometer (Berthold Analytical Instruction).

\section{Renilla Luciferase Assay}

The phRL-TK vector was purchased from Promega Corporation (Madison, Wisconsin). Two $\mu \mathrm{g}$ phRL-TK vector and $3 \mu \mathrm{g}$ pNF- $\kappa \mathrm{B}$-Luc Vector (Mercury Pathway Profiling System) were transfected with $10 \mu \mathrm{M}$ cFLIP antisense or $10 \mu \mathrm{M}$ cFLIP sense oligodeoxynucleotides using FuGENE 6 (Boehringer Mannheim), essentially according to the manufacture's protocol, for 24 hours at $37^{\circ} \mathrm{C}$. Renilla luciferase activity was determined from cell extracts by means of a renilla luciferase assay system (Promega) and luminometer (Berthold Analytical Instruction). The value of $N F-\kappa B$ luciferase activities were modulated by the value of renilla luciferase activities.

\section{HCC Cell Stimulation by NF-кB Activation or Phosphatidylinostiol-3 (PI-3)/Akt Kinase Activation}

To analyze the effect for cFLIP protein expression in $\mathrm{HCC}$ cells mediated by the NF- $\kappa \mathrm{B}$ activation pathway, $2 \times 10^{5} \mathrm{HCC}$ cells were incubated with $50 \mathrm{ng} / \mathrm{ml}$ TRAIL (R\&D Systems) or 50 ng/ml TNF- $\alpha$ (Cosmo Bio) for 24 hours. With respect to Pl-3/Akt kinase pathway, we used $100 \mathrm{ng} / \mathrm{ml}$ recombinant human VEGF (Peprotech EC Ltd., London, United Kingdom) or 200 nM wortmannin (SIGMA). Expression of cFLIP protein was analyzed by Western blotting.

\section{References}

Barkett M and Gilmore T (1999). Control of apoptosis by Rel/NF- $\kappa$ B transcription factors. Oncogene 18:6910-6924.

Barnes PJ and Karin M (1997). Nuclear factor- $\kappa$ B: A pivotal transcription factor in chronic inflammatory diseases. N Eng J Med 336:1066-1107.

Bazzani F and Beutler B (1996). The tumor necrosis factor ligand and receptor families. N Eng J Med 334:1717-1725.

Beg AA, Sha WC, Bronson RT, Ghosh S, and Baltimore D (1995). Embryonic lethality and liver degeneration in mice lacking the RelA component of NF- $\kappa$ B. Nature 376:167-170.

Bernard D, Quatannens B, Vandenbunder B, and Abbadie C (2001). Rel/NF- $\kappa$ B transcription factors protect against tumor necrosis factor (TNF)-related apoptosis-inducing ligand (TRAIL)-induced apoptosis by up-regulating the TRAIL decoy receptor DcR1. J Biol Chem 276:27322-27328.

Bullani RR, Huard B, Viard-Leveugle I, Byers HR, Irmler M, Saurat JH, Tschopp J, and French LE (2001). Selective 
expression of FLIP in malignant melanocytic skin lesions. $J$ Invest Dermatol 117:360-364.

Chinnaiyan AM, Tepper CG, Seldin MF, O'Rourke K, Kischkel FC, Hellbardt S, Krammer PH, Peter ME, and Dixit VM (1996). FADD/MORT1 is a common mediator of CD95 (Fas/APO-1) and tumor necrosis factor receptor-induced apoptosis. J Biol Chem 271:4961-4965.

Chow NH, Hsu PI, Lin XZ, Yang HB, Chan SH, Cheng KS, Huang SM, and Su IJ (1997). Expression of vascular endothelial growth factor in normal liver and hepatocellular carcinoma: An immunohistochemical study. Hum Pathol 28: 698-703.

Degli-Esposti MA, Dougall WC, Smock PJ, Waugh JY, Smith CA, and Goodwin RG (1997). The novel receptor TRAIL-R4 induces NF- $\kappa$ B and protects against TRAIL-mediated apoptosis, yet retains an incomplete death domain. Immunity 7:813-820.

Djerbi M, Screpanti V, Catrina Al, Bogen B, Biberfeld P, and Grandien A (1999). The inhibitor of death receptor signaling, FLICE-inhibitory protein defines a new class of tumor progression factors. J Exp Med 190:1025-1032.

Fujikawa K, Shiraki K, Sugimoto K, Ito T, Yamanaka T, Takase K, and Nakano T (2000). Reduced expression of ICE/caspase1 and CPP32/caspase3 in human hepatocellular carcinoma. Anticancer Res 20:1927-1932.

Fulda S, Meyer E, and Debatin KM (2000). Metabolic inhibitors sensitize for CD95 (APO-1/Fas)- induced apoptosis by down-regulation Fas-associated death domain-like interleukin 1-coverting enzyme inhibitory protein expression. Cancer Res 60:3947-3956.

Goltsev YV, Kovalenko AV, Arnold E, Varfolomeev EE, Brodianskii VM, and Wallach D (1997). CASH: A novel caspase homologue with death effector domains. J Biol Chem 272: 19641-19644.

Griffith TS and Lynch DH (1998). TRAIL: A molecule with multiple receptors and control mechanisms. Curr Opin Immunol 10:559-563.

Gura T (1997). How TRAIL kills cancer cells, but not normal cells. Science 277:768.

Harper N, Farrow SN, Kaptein A, Cohen GM, and MacFarlane M (2001). Modulation of tumor necrosis apoptosis-inducing ligand-induced $\mathrm{NF}-\kappa \mathrm{B}$ activation by inhibition of apical caspases. J Biol Chem 276:34743-34752.

Hu S, Vincenz C, Jian N, Gentz R, and Dixit VM (1997). I-FLICE: A novel inhibitor of tumor necrosis factor receptor-1 and CD-95-induced apoptosis. J Biol Chem 272:1725517257.

Inoue J, Ishida T, Tsukamoto N, Kobayashi N, Naito A, Azuma S, and Yamamoto T (2000). Tumor necrosis factor receptor-associated factor (TRAF) family: Adapter proteins that mediate cytokine signaling. Exp Cell Res 254:14-24.

Irmler M, Thome M, Hahne M, Schneider P, Hofmann K, Steiner V, Bodmer JL, Schröter M, Burns K, Mattmann C, Rimoldi D, French LE, and Tschopp J (1997). Inhibition of death receptor signals by cellular FLIP. Nature 388:190-195.

Ito T, Shiraki K, Sugimoto K, Yamanaka T, Fujikawa K, Ito M, Takase K, Moriyama M, Kawano H, Hayashida M, Nakano T, and Suzuki A (2000). Survivin promotes cell proliferation in human hepatocellular carcinoma. Hepatology 31:10801085.
Kataoka T, Budd RC, Holler N, Thome M, Martinon F, Irmler M, Burns K, Hahne M, Kennedy N, Kovacsovics M, and Tschopp J (2000). The caspase-8 inhibitor FLIP promoters activation of NF- $\kappa \mathrm{B}$ and Erk signaling pathways. Curr Biol 10:640-648.

Khoshnan A, Tindell C, Laux I, Bae D, Bennett B, and Nel AE (2000). The NF-kappaB cascade is important in Bcl-xL expression and for the anti-apoptotic effects of the CD28 receptor in primary human CD4+ lymphocytes. J Immunol 165:1743-1754.

Kischkel FC, Hellbardt S, Behrmann I, Germer M, Pawlita M, Krammer PH, and Peter ME (1995). Cytotoxicity-dependent APO-1(Fas/CD95)-associated proteins form a deathinducing signaling complex (DISC) with the receptor. EMBO J 14:5579-5588.

Krammer PH (1999). CD95 (APO-1/Fas)-mediated apoptosis: Live and let die. Adv Immuniol 71:163-210.

Krueger A, Baumann S, Krammer PH, and Kirchhoff S (2001). FLICE-inhibitory proteins: Regulators of death receptormediated apoptosis. Mol Cell Biol 21:8247-8254.

Locksley RM, Killeen N, and Lenardo MJ (2001). The TNF and TNF receptor superfamilies: Integrating mammalian biology. Cell 104:487-501.

Medema JP, de Jong D, van Hall T, Melief CJ, and Offringa R (1999). Immune Escape of Tumors In Vivo by Expression of Cellular FLICE-inhibitory Protein. J Exp Med 190:1033-1038.

Medema JP, Scaffidi C, Kischkel FC, Shevchenko A, Mann M, Krammer PH, and Peter ME (1997). FLICE is activated by association with the CD95 death-inducing signaling complex (DISC). EMBO J 16:2794-2804.

Muzio M, Chinnaiyan AM, Kischkel FC, O'Rourke K, Shevchenko A, Ni J, Scaffidi C, Bretz JD, Zhang M, Gentz R, Mann M, Krammer PH, Peter ME, and Dixit VM (1996). FLICE, a novel FADD-homologous ICE/CED-3-like protease, is recruited to the CD95 (Fas/APO-1) death-inducing signaling complex. Cell 85:817-827.

Nagata S (1997). Apoptosis by death factor. Cell 88:355-365.

Natoli G, lanni A, Costanzo A, De Petrillo G, Ilari I, Chirillo P, Balsano C, and Levrero M (1995). Resistance to Fasmediated apoptosis in human hepatoma cells. Oncogene 11:1157-1164.

Perlman H, Pagliari LJ, Georganas C, Mano T, Walsh K, and Pope RM (1999). FLICE-inhibitory protein expression during macrophage differentiation confers resistance to fasmediated apoptosis. J Exp Med 190:1679-1688.

Ponton A, Clement MV, and Stamenkovic I (1996). The CD95 (APO-1/Fas) receptor activates NF- $\kappa$ B independently of its cytotoxic function. J Biol Chem 271:8991-8995.

Rayet B and Gelinas C (1999). Aberrant rel/nfkb genes and activity in human cancer. Oncogene 22:6938-6947.

Robinson D, Shibuya K, Mui A, Zonin F, Murphy E, Sana T, Hartley SB, Menon S, Kastekein R, Bazan F, and O'Rarra A (1997). IGIF does not drive Th1 development but synergizes with IL-12 for interferon-gamma production and activates IRAK and NFkappaB. Immunity 4:571-581.

Ryu BK, Lee MG, Chi SG, Kim YW, and Park JH (2001). Increased expression of cFLIP (L) in colonic adenocarcinoma. J Pathol 194:15-19.

Schmid RM and Adler G (2000). NF- $\kappa$ B/Rel// $\kappa$ B: Implication in gastrointestinal diseases. Gastroenterology 118:1208-1228. 
Schulte-Hermann R, Bursch W, Low-Baselli A, Wanger A, and Grasl-Kraupp B (1997). Apoptosis in the liver and its role in hepatocarcinogenesis. Cell Biol Toxicol 13:339-348.

Seitz C, Müller P, Krieg RC, Männel DN, and Hehlgans T (2001). A novel p75TNF receptor isoform mediating $\mathrm{NF} \kappa \mathrm{B}$ activation. J Biol Chem 276:19390-19395.

Shi Y, Hsu JH J, Hu L, Gera J, and Lichtenstein A (2002). Signal pathways involved in activation of p70S6 and phosphorylation of 4E-BP1 following exposure of multiple myeloma tumor cells to interleukin-6. J Biol Chem 277:1571215720.

Shiraki K, Takase K, and Nakano T (2002). The emerging role of caspase inhibitors in gastrointestinal cancers. J Gastroenterol 37:323-331.

Shu HB, Halpin DR, and Goeddel DV (1997). Casper is a FADD- and caspase-related inducer of apoptosis. Immunity 6:751-763.

Soini Y, Virkajärvi N, Letho VP, and Pääkkö P (1996). Hepatocellular carcinomas with a high proliferation index and a low degree of apoptosis and necrosis are associated with a shorter survival. Br J Cancer 73:1025-1030.

Srinivasula SM, Ahmad M, Ottilie S, Bullrich F, Banks S, Wang Y, Alnemri TF, Croce CM, Litwack G, Tomaselli KJ, Armstrong RC, and Alnemri ES (1997). FLAME-1, a novel FADD-like anti-apoptotic molecule that regulates Fas/ TNFR1-induced apoptosis. J Biol Chem 272:18542-18545.

Strand S, Hofmann WJ, Hug H, Muller M, Otto G, Strand D, Mariani SM, Stremmel W, Krammer PH, and Galle PR (1996). Lymphocyte apoptosis induced by CD95 (APO-1/Fas) ligand expressing tumor cells: A mechanism of immune evasion? Nat Med 2:1361-1366.

Sugimoto K, Shiraki K, Ito T, Fujikawa K, Takase K, Tameda Y, Moriyama M, and Nakano T (1999). Expression of functional CD40 in human hepatocellular carcinoma. Hepatology 30:920-926.

Suzuki A, Hayashida M, Kawano $\mathrm{H}$, Sugimoto $\mathrm{K}$, Nakano $\mathrm{T}$, and Shiraki K (2000). Hepatocyte growth factor promotes cell survival from Fas-mediated cell death in hepatocellular carcinoma cells via Akt activation and Fas-death-inducing signaling complex suppression. Hepatology 4:796-802.

Takehara T, Liu X, Fujimoto J, Friedman SL, and Takahashi H (2001). Expression and role of $\mathrm{Bcl}-\mathrm{xL}$ in human hepatocellular carcinomas. Hepatology 34:55-61.

Tepper CG and Seldin MF (1999). Modulation of caspase-8 and FLICE-inhibitory protein expression as a potential mechanism of Epstein-Barr virus tumorigenesis in Burkitt's lymphoma. Blood 94:1727-1737.

Thome M, Schneidei P, Hofmann K, Fickenscher H, Meinl E, Neipel F, Mattmann C, Burns K, Bodmer JL, Schröter M, Scaffidi C, Krammer PH, Peter ME, and Tschopp J (1997). Viral FLICE-inhibitory proteins (FLIPs) prevent apoptosis induced by death receptors. Nature 386:517-521.
Thompson CB (1995). Apoptosis in the pathogenesis and treatment of disease. Science 267:1456-1462.

Thorgeirsson SS, Teramoto T, and Factor VM (1998). Dysregulation of apoptosis in hepatocellular carcinoma. Semin Liver Dis 18:115-122.

Thornberry NA and Lazebnik Y (1998). Caspases: Enemies within. Science 281:1312-1316.

Vaux DL, Haecker G, and Strasser A (1994). An evolutionary perspective on apoptosis. Cell 76:777-779.

Wajant H, Haas E, Schwenzer R, Mühlenbeck F, Kreuz S, Schubert G, Grell M, Smith C, and Scheurich P (2000). Inhibition of death receptor-mediated gene induction by a cycloheximide-sensitive factor occurs at the level of or upstream of Fas-associated death domain protein (FADD). J Biol Chem 275:24357-24366.

Wang CY, Mayo MW, Korneluk RG, Goeddel DV, and Baldwin AS Jr (1998). NF-kappaB antiapoptosis: Induction of TRAF1 and TRAF2 and C-IAP and C-IAP2 to suppress caspase-8 activation. Science 281:1680-1683.

Wang J, Lobito AA, Shen F, Hurnung F, Winoto A, and Lenardo MJ (2000). Inhibition of Fas-mediated apoptosis by the $\mathrm{B}$ cell antigen receptor through c-FLIP. Eur J Immunol 30:155-163.

Willems F, Amraoui Z, Vanderheyde N, Verhasselt V, Aksoy E, Scaffidi C, Peter ME, Krammer PH, and Goldman M (2000). Expression of c-FLIPL and resistance to CD95-mediated apoptosis of monocyte-derived dendritic cells: Inhibition by bisindolylmaleimide. Blood 95:3478-3482.

Yamaguchi R, Yano H, lemura A, Ogasawara S, Haramaki M, and Kojiro M (1998). Expression of vascular endothelial growth factor in human hepatocellular carcinoma. Hepatology 28:68-77.

Yamanaka T, Shiraki K, Sugimoto K, Ito T, Fujikawa K, Ito M, Takase K, Moriyama M, Nakano T, and Suzuki A (2000). Chemotherapeutic agents augment TRAIL-induced apoptosis in human hepatocellular carcinoma cell lines. Hepatology 32:482-490.

Yeh WC, Itie A, Elia AJ, Ng M, Shu HB, Wakeham A, Mirtsos C, Suzuki N, Bonnard M, Goeddel DV, and Mak TW (2000). Requirement for Casper (c-FLIP) in regulation of death receptor-induced apoptosis and embryonic development. Immunity 6:633-642. 